\title{
REFLEXÕES SOBRE A ATUAÇÃO DO INTÉRPRETE DE LÍNGUA DE SINAIS NA MEDIAÇÃO DA AVALIAÇÃO CLÍNICA EM SERVIÇO DE SAÚDE MENTAL
}

\author{
REFLECTIONS ON THE SIGN LANGUAGE INTERPRETER PERFORMANCE \\ MEDIATING THE CLINICAL ASSESSMENT IN MENTAL HEALTH SERVICE
}

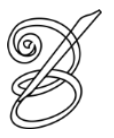 \\ Felipe Venâncio BARBOSA ${ }^{\mathrm{i}}$ \\ Universidade de São Paulo \\ Janice Gonçalves Temoteo MARQUES ${ }^{\mathrm{ii}}$ \\ Universidade Estadual de Campinas \\ Leonardo Augusto Negreiros Parente Capela SAMPAIO \\ Universidade de São Paulo
}

\begin{abstract}
Resumo: A mediação da relação entre médico psiquiatra e paciente surdo pelo intérprete de língua de sinais deve levar em consideração aspectos frequentemente negligenciados em interações fora do ambiente de saúde. Expressões atípicas da língua de sinais podem ocorrer nessa relação em decorrência de desordens psiquiátricas, demandando do intérprete de língua de sinais sensibilidade e aptidão para realizar o processo de interpretação de forma eficaz, levando para o médico as informações necessárias para a composição do diagnóstico e seguimento. O objetivo deste artigo é discutir a atuação do intérprete de língua de sinais na mediação da comunicação na relação médico-paciente em ambulatório de saúde mental de um hospital terciário em São Paulo. A discussão terá ênfase em questões de ordem pragmática e na análise e interpretação da qualidade de sinalização, tomando como linha organizadora os dados comumente observados no Exame Psíquico conduzido por médico psiquiatra, com a atuação do intérprete de língua de sinais. A atuação do profissional na mediação é determinante para a condução do diagnóstico em saúde mental e influencia a qualidade do cuidado. Os aspectos linguísticos que podem ser expressos de forma atípica não devem ser omitidos pelo intérprete de língua de sinais, mas veiculados de forma imparcial, desde aquelas que provocam quebras comunicativas na interação até aquelas que, mesmo sem provocar quebras comunicativas, carregam informações pertinentes à história clínica e indicação terapêutica.

Palavras-chave: Interpretação simultânea. Relação médico-paciente. Língua de sinais atípica.
\end{abstract}

Abstract: The mediation of the relationship between psychiatrist and deaf patient by the Sign Language Interpreter must take into account aspects often overlooked in interactions outside the healthcare setting. Atypical expressions of sign language may occur in this relationship as a result of psychiatric disorders, requiring of the Sign Language Interpreter to be sensitive and able to perform the interpretation process effectively by providing to the Doctor the necessary information for the composition of the diagnosis and follow-up. The purpose of this paper is to discuss the work of the Sign Language Interpreter during the mediation of communication of doctor-patient relationship in a mental health outpatient clinic of a tertiary hospital in the city of Sao Paulo, Brazil. The discussion will focus on pragmatic issues and on the analysis and interpretation of the quality of signing taking as the organizing line the data commonly observed in the Mental Examination conducted by a psychiatrist, with the performance of the Sign Language Interpreter. The performance of the Sign Language Interpreter in a professional medical mediation is crucial to the conduct of the diagnosis in mental health clinic and influences the quality of care. Linguistic aspects that can be expressed in an atypical way of signing should not be omitted by the Sign Language Interpreter, but served impartially,

BARBOSA, MARQUES, SAMPAIO. Reflexões sobre a atuação do intérprete de língua de sinais na mediação da avaliação clínica em serviço de saúde mental

Belas Infiéis, v. 8, n. 1, p. 229-250, 2019. DOI: 10.26512/belasinfieis.v8.n1.2019.12985 
from those that cause communicative breaks in the interaction to those that, even without causing communicative breaks, carry pertinent information to the medical history and therapy management.

Key-words: Simultaneous interpreting. Doctor-patient relationship. Atypical sign language.

RECEBIDO EM: 20 de março de 2018

ACEITO EM: 25 de novembro de 2018

PUBLICADO EM: janeiro 2019

\section{Introdução}

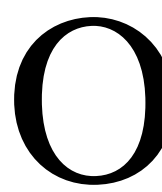

atendimento ao paciente surdo deve ser feito de forma a priorizar a língua que utiliza em sua comunicação. Para os pacientes surdos sinalizantes, aqueles que usam a língua de sinais e a reconhecem como sua primeira língua, o atendimento deve ser,

preferencialmente, feito em língua de sinais. Na ausência de profissional de saúde que possua o domínio da língua de sinais, há a necessidade da presença de um profissional intérprete de língua de sinais capacitado para fazer a mediação durante o atendimento e possibilitar que a relação médico-paciente ocorra de modo otimizado.

De acordo com Flores (2005), diversos estudos apontam para o incremento da qualidade dos serviços de saúde na presença de intérpretes de línguas, com impactos importantes na qualidade do cuidado e na compreensão dos pacientes. A atuação do intérprete de língua de sinais em ambientes de saúde tem o intuito de mediar os atendimentos que envolvem o paciente surdo e um profissional de saúde por meio do uso da língua de sinais. Para isso, esse profissional intérprete de língua de sinais deve ser capacitado para exercer sua função, dominando as línguas com as quais vai atuar e desenvolvendo, com formação apropriada, habilidades específicas para o exercício da profissão e dentre ela, o domínio dos vários tipos e modalidades de interpretação, como da interpretação simultânea e da interpretação consecutiva. Esse processo, quando realizado por profissional com formação em estudos da tradução, não apresenta diferença significativa quando comparado ao atendimento realizado por profissional bilíngue que não obrigatoriamente terá habilidades tradutórias para a realização adequada do processo, de acordo com Farooq; Fear; Oyebode (1997).

A interpretação simultânea é caracterizada pela mobilização de diversas funções cognitivas em um mesmo momento. A recepção e compreensão das informações emitidas na língua fonte, a 
conversão dessas informações para a língua alvo, a escolha das informações relevantes a serem veiculadas junto ao planejamento da produção da informação na língua alvo e a produção em si ocorrem, em parte, simultaneamente, demandando grande esforço cognitivo (GILE, 1995; LEE, 2002). No processo de interpretação simultânea realizado pelo intérprete de língua de sinais na mediação da comunicação entre uma pessoa surda e uma pessoa ouvinte, além das diversas funções cognitivas mobilizadas, há ainda o envolvimento de duas diferentes modalidades de língua: uma língua oral-auditiva e uma língua visuoespacial, a língua de sinais. Por esse motivo, neste processo deve ser considerada uma questão de ordem motora, visto que as línguas de modalidade oralauditiva usam recursos físicos corporais diferentes dos usados pelas línguas de modalidade visuoespacial.

Nesse processo simultâneo, as produções interpretadas trazem consigo diversas informações de cunho linguístico, emocional, cultural e situacional que podem ser interpretadas e adaptadas pelo profissional intérprete de língua de sinais. Por se tratar de um processo simultâneo de recepção e produção de línguas, exige grande habilidade e tomadas de decisões interpretativas em tempo exíguo. A observação e identificação de padrões alterados ou atípicos no discurso do emissor da mensagem é de grande importância no processo de avaliação linguística, que pode ser realizada, com objetivos e olhares diferentes, por profissionais da Fonoaudiologia, da Psicologia, da Psiquiatria e da Educação. Do ponto de vista da relação médico-paciente em saúde mental, a avaliação psicopatológica é a ferramenta principal para avaliar o estado mental do paciente. Este roteiro de aferição de funções psíquicas condensa os achados da entrevista psiquiátrica em eixos temáticos para ajudar na construção diagnóstica. Com ele, observam-se não apenas as características comportamentais do paciente (surdo, no caso desta discussão), mas também o conteúdo de sua produção e a qualidade em que essa produção é externalizada.

Assim como as línguas orais, as línguas de sinais podem sofrer influência de quadros de desordens psiquiátricas, como indica o trabalho de Barbosa (2016), produzindo uma expressão atípica do processamento da língua. Nesses casos, qualquer um dos níveis do processamento linguístico pode estar alterado, de forma transitória ou não, provocando quebras na compreensão e/ou expressão em um ou mais níveis - fonético-fonológico, lexical, sintático, discursivo ou pragmático (BARBOSA, 2007, 2010; ATKINSON et al., 2005; MASON et al.,2010; WOLL; MORGAN, 2012; BARBOSA; NEVES, 2017).

BARBOSA, MARQUES, SAMPAIO. Reflexões sobre a atuação do intérprete de língua de sinais na mediação da avaliação clínica em serviço de saúde mental

Belas Infiéis, v. 8, n. 1, p. 229-250, 2019. DOI: 10.26512/belasinfieis.v8.n1.2019.12985 
Em situações em que o conteúdo e a forma interpretada na língua alvo são relevantes, por exemplo, para um diagnóstico psicopatológico (FLORES, 2005), o cuidado do intérprete de língua de sinais deve ser, além de transmitir para a língua alvo o maior número de informações sobre o conteúdo emitido na língua fonte, apresentar, na língua alvo, outras informações linguísticas pertinentes ao objetivo da interação. O Exame Psíquico (EP) e a Súmula Psicopatológica realizados para o diagnóstico em saúde mental produzem um conjunto de informações comportamentais e linguísticas que extrapolam a referencialidade do conteúdo das mensagens (FERREIRA; NETTO, 2009). O Exame Psíquico avalia as faculdades mentais que podem estar alteradas por condições clínicas, como transtornos mentais. A Súmula Psicopatológica resume, em poucos jargões, estes achados, facilitando a leitura rápida por outra pessoa treinada em Psicopatologia. O domínio metalinguístico da pragmática e o domínio da identificação de aspectos prosódicos e da qualidade de sinalização, nesses casos, são imprescindíveis, tanto para o clínico quanto para o intérprete de língua de sinais.

A Pragmática ${ }^{1}$ é uma das áreas de estudo das ciências da linguagem e tem como objetivo 232 o estudo das habilidades do uso da língua e da linguagem nas interações entre as pessoas (DEWART; SUMMERS, 1994; FERNANDES, 1996; SAVIGNON, 2007; CUMMINGS, 2010; BARBOSA; LICHTIG, 2014), como, por exemplo, em uma consulta médica. Os estudos dessa área observam, entre diversos fatores, as intenções e atitudes que são tomadas enquanto o falante está usando seu turno comunicativo, como cede e toma o turno comunicativo, como faz uso da prosódia da língua ou de gestos, assim como mobiliza componentes não linguísticos que acompanham a fala (ou a sinalização) para se comunicar. A ênfase da pragmática, segundo esses autores, está no diálogo, considerando principalmente o contexto situacional. Os procedimentos usados para a análise pragmática de situações de comunicação têm incluído a compreensão e produção de palavras, frases e sentenças em ambientes naturais de comunicação, práticas de regras conversacionais e aplicação das habilidades não verbais, e significados para a eficiência comunicativa (HOUGH; PIERCE, 1993).

Em uma análise conversacional é necessário que, por exemplo, se observe a organização das trocas conversacionais, como a manutenção e troca de turno referidas. Problemas pragmáticos dessa ordem geralmente são mascarados pela cooperação entre os interlocutores (CHANTRAINE et al., 1998), que, em momentos em que naturalmente ocorrem assaltos de turnos indevidos (as 
sobreposições de linhas nas interações) acionam recursos de correção ou modalização discursiva para que a comunicação ocorra de forma adequada. No entanto, as sobreposições de linhas, quando ocorrem em demasia, indicam inadequações na manutenção e troca de turno e, portanto, alterações em habilidades pragmáticas que podem ser sinais clínicos (BARBOSA, 2017).

Algumas habilidades que podem ser observadas em uma interação são as propostas por Gerber e Gurland (1989) em um inventário de avaliação pragmática em que são observadas as habilidades linguístico-pragmáticas preservadas e alteradas. As autoras propõem a observação dos problemas linguísticos que causam quebras fonológicas, lexicais e sintático-semânticas e de problemas pragmáticos, com possibilidades de quebras de irrelevância contextual (quando o paciente realiza uma expressão sem relevância para o contexto conversacional), quebras de mudança e manutenção de tópico (falha na manutenção ou mudança do tema da conversa com desvio do assunto vigente ou perseveração em um assunto específico), mudança de turno (quando o paciente não consegue perceber os momentos propícios para a tomada de turno ou não exibe deixas para que o interlocutor tome o turno) e repetição da emissão do interlocutor. Da mesma forma, em pessoas surdas, são observadas alterações nas habilidades linguístico-pragmáticas, como afirmam os estudos de Barbosa $(2016,2017)^{2}$ sobre a presença de atipias na produção e compreensão da língua de sinais por indivíduos surdos.

A fala e a voz são essenciais na comunicação realizada em uma língua oral-auditiva. A qualidade da voz e da fala pode indicar características físicas e psíquicas dos indivíduos (COSTA; MATIAS, 2005; CASSOL et al, 2010), sendo de grande importância para o diagnóstico clínico em saúde mental. Mesmo que a informação não seja veiculada de forma explícita por uma pessoa, o profissional que analisa o discurso pode perceber, nas entrelinhas, características que o ajudarão a fazer o diagnóstico e tomar a decisão clínica mais adequada. Alterações de exame psíquico podem ser observadas por elementos linguísticos como fala, voz, léxico utilizado, repercussão do discurso que se deseja imprimir no interlocutor, etc. Nas línguas de sinais, essas características percebidas nas entrelinhas da fala (sinalização) estão relacionadas à qualidade da produção sinalizada.

A qualidade da produção sinalizada, outra característica importante na identificação da língua de sinais atípica, é observada levando em consideração aspectos fonéticos perceptíveis que integram a produção linguística de pessoas surdas, tomando como base a apreciação do interlocutor de itens segmentais e suprassegmentais da língua de sinais. Andrade et al. (2017) apresentam uma

BARBOSA, MARQUES, SAMPAIO. Reflexões sobre a atuação do intérprete de língua de sinais na mediação da avaliação clínica em serviço de saúde mental

Belas Infiéis, v. 8, n. 1, p. 229-250, 2019. DOI: 10.26512/belasinfieis.v8.n1.2019.12985 
escala de Análise da Qualidade da Transmissão da Mensagem que propõe a observação de expressões faciais gramaticais (da sintaxe da língua) e associadas (por exemplo, de ordem expressiva/emocional), da movimentação corporal, do ritmo da sinalização, da qualidade do movimento e forma das mãos, da posição espacial dos sinais, da orientação da palma das mãos e do número de mãos usado na sinalização.

Embora essas análises sejam subjetivas, a base do reconhecimento da atipia na qualidade da produção sinalizada é realizada pela competência linguística do observador, nesse caso, o intérprete de língua de sinais. Da mesma forma que indivíduos fluentes em língua de sinais possuem condições de reconhecer sentenças agramaticais na língua que domina, a qualidade da produção sinalizada pode ser identificada por indivíduos fluentes. Para o intérprete de língua de sinais, entretanto, essa tarefa deve ser filtrada pela análise metalinguística e os componentes da qualidade da produção sinalizada devem ser identificados e, em casos específicos, informados.

O objetivo deste artigo é apresentar reflexões sobre a atuação do intérprete de língua de sinais na mediação da avaliação clínica de pessoas surdas em serviço de saúde mental em um hospital terciário ${ }^{3}$ em São Paulo. A discussão terá ênfase em questões de ordem pragmática, especificamente da pragmática clínica (CUMMINGS, 2010), e na análise e interpretação da qualidade de sinalização, tomando como linha organizadora os dados comumente observados no EP conduzido por psiquiatra, com a atuação do intérprete de língua de sinais.

Do ponto de vista metodológico, as discussões que serão apresentadas aqui partem da experiência de uma equipe interdisciplinar formada por três profissionais, um da área de tradução e interpretação de língua de sinais, um da fonoaudiologia e um da área médica. Esta equipe desenvolveu atuação semanal com pacientes surdos e intérpretes de língua de sinais em serviço de saúde mental e em discussões dos casos que fizeram parte da rotina do serviço referido. No desenvolvimento das atividades, em conjunto com os intérpretes participantes e com o corpo médico, construiu procedimentos na mediação da avaliação clínica em saúde mental que apresentou resultados satisfatórios para a equipe médica envolvida e para o desenvolvimento do processo terapêutico dos pacientes surdos.

Em nosso serviço, os pacientes surdos são atendidos por médicos residentes de Psiquiatria junto ao intérprete de língua de sinais profissionais e voluntários, com formação em nível superior e com experiência mínima de oito anos de atuação como intérprete de língua de sinais, 
supervisionados pela equipe interdisciplinar referida. Finalizado o atendimento médico inicial, médico e intérprete discutem o caso com o médico assistente, onde são discutidos elementos clínicos do caso e questões linguísticas ou de interpretação que tenham surgido no atendimento. Médico e intérprete retornam à sala para dar a devolutiva ao paciente e agendar o retorno. Também são realizadas avaliações fonoaudiológicas e linguísticas por profissional fonoaudiólogo e linguista.

As discussões que serão apresentadas serão baseadas na experiência deste serviço, entretanto não apresentará dados explícitos, análise de produções ou exemplos com trechos e situações de interpretação. Esta escolha se deu por questões éticas relacionadas ao compromisso médico de confidencialidade e sigilo com relação aos conteúdos que transitam em uma clínica de saúde mental. Consideramos que, embora a presença de exemplos e dados objetivos viesse a enriquecer a discussão, os apontamentos que fazemos neste trabalho são importantes para as reflexões sobre técnicas de interpretação e podem contribuir para o desenvolvimento dos estudos da área e para a formação de intérpretes.

Ao avaliar um paciente em sofrimento psíquico, o médico faz um conjunto de observações clínicas que são aferidas diretamente do comportamento e do discurso do sujeito em consulta. Participando de uma consulta em que estes dados são mediados pelo intérprete de língua de sinais, psiquiatra e intérprete de língua de sinais precisam estar alinhados em sua prática para garantir que os dados analisados sejam oriundos das produções do cliente, e não do tradutor.

Em várias situações este pode ser um complicador que simula condições psiquiátricas ou disfarça achados positivos na avaliação clínica. A experiência clínica observada pela equipe mostra que a tentativa do intérprete de língua de sinais de corrigir um discurso confuso para torná-lo inteligível para o clínico pode dissimular um discurso psicótico em quadro de esquizofrenia ainda discreto. $\mathrm{O}$ intérprete de língua de sinais pode também não ressaltar uma aceleração na velocidade de sinalização, que para ele é evidente e potencialmente irrelevante, mas pode dificultar o diagnóstico de uma fase maníaca do transtorno afetivo bipolar. Não seria necessariamente relevante acelerar a velocidade da fala no momento da interpretação, simulando a alteração de discurso observada. Esta estratégia pode ser de difícil reprodução por parte do intérprete de língua de sinais (que precisaria falar como um paciente bipolar ouvinte) e poderia gerar estranhamento por parte do médico. Ao final da consulta, é interessante que médico e intérprete tenham um momento para 
discutir o atendimento, minimizando dúvidas sobre a interpretação e repassando achados relevantes do EP.

\section{O Exame Psíquico, as alterações psíquicas e a mediação pelo intérprete de língua de sinais}

A Psicopatologia é a via de acesso ao mundo psíquico do paciente psiquiátrico. O Exame Psíquico e a Súmula Psicopatológica são o resultado da avaliação clínica, sendo composta de anamnese, testes não estruturados para funções psíquicas específicas e, eventualmente, questionários ou testes estruturados. Para chegar a um diagnóstico e realizar uma indicação terapêutica psicofarmacológica ou psicoterápica, o psiquiatra colhe a história clínica subjetiva com o paciente e, se necessário, a história objetiva com familiares ou acompanhantes. A sensibilidade psicopatológica do profissional é aperfeiçoada durante sua formação e com a experiência clínica, tornando possível reconhecer apresentações típicas e atípicas dos diagnósticos psiquiátricos e de apresentações psicopatológicas.

Se durante a consulta psiquiátrica com ouvintes os dados clínicos são colhidos por meio da observação dos fenômenos psicopatológicos in natura manifestados pelo paciente durante a consulta, com surdos a coleta de informações relevantes à composição do diagnóstico é mediada pelo intérprete de língua de sinais. Nesse sentido, faz-se necessário que o intérprete em atuação no contexto de saúde (profissionais com especialização em interpretação na área da saúde) esteja atento às nuances do EP para não supervalorizar, desvalorizar ou modificar apresentações de dados psicopatológicos.

No EP são observados pontos específicos que passam a ser discutidos em conjunto com a atuação do intérprete de língua de sinais, tomando como foco a pragmática e a qualidade da produção sinalizada:

Aparência, apresentação, atitude e contato. Neste ponto, o Psiquiatra avalia os dados de acesso mais imediato. Aqui são observados itens como vestimentas e adereços, autocuidado, aparência física, movimentação, expressões faciais e postura corporal. A forma como o paciente se coloca na consulta também é de extrema importância, já que o negativismo (de uma depressão psicótica), a hostilidade (de um paciente esquizofrênico) e a inadequação social (em um portador de transtorno bipolar) são dados que precisam chegar ao médico para que ele possa dar um diagnóstico preciso (RAMOS, 2006).

BARBOSA, MARQUES, SAMPAIO. Reflexões sobre a atuação do intérprete de língua de sinais na mediação da avaliação clínica em serviço de saúde mental

Belas Infiéis, v. 8, n. 1, p. 229-250, 2019. DOI: 10.26512/belasinfieis.v8.n1.2019.12985 
$\mathrm{Na}$ consulta com o paciente surdo, esses dados serão mediados pelo intérprete de língua de sinais, podendo ser omitidos por algum desconforto do intérprete em, por exemplo, falar palavrões ou ser intrusivo com o psiquiatra. A atitude e o contato durante a consulta, portanto, podem se apresentar com diferentes graus de inadequação, por exemplo, com a intervenção do paciente no discurso com ruptura do turno comunicativo do médico, com proposições irrelevantes ou até mesmo com insultos que podem, por vezes, ser atenuados pelo intérprete de língua de sinais no intuito de proteger uma das partes da interação. Essas práticas foram referidas pelos profissionais participantes do serviço nas discussões de caso dos atendimentos.

A intervenção do intérprete de língua de sinais na adequação/organização pragmática em uma conversa não é algo raro. Muitas vezes, em um momento de assalto de turno realizado pela pessoa surda, em uma sobreposição ou na insistência na manutenção do turno comunicativo, essas intervenções são modalizadas pelo intérprete de língua de sinais para que a interação entre a pessoa surda e a pessoa ouvinte ocorra de forma harmônica. Por isso, o intérprete de língua de sinais precisa estar preparado para administrar essas situações (METZGER, 2000; VAN HERREWEGHE, 2005). Em interações pragmaticamente conflituosas, o intérprete de língua de sinais pode pedir, por exemplo, para que a pessoa surda espere seu turno ou simplesmente pode ignorar a fala sobreposta de um ou de outro interlocutor.

A interrupção do turno comunicativo do interlocutor pode vir carregada de informações importantes para o EP. Os assaltos de turno frequentes realizados pelo paciente em avaliação podem representar, por exemplo, sinais de impulsividade ou ansiedade. Observamos que para a boa condução da prática clínica, a interpretação da sinalização do surdo no ato de sua produção, independente da tomada de turno apropriada, é mais efetiva quando realizada de forma que o médico possa perceber a ruptura e tomar as medidas comunicativas como o interlocutor.

Consciência. Os níveis de consciência traduzem o funcionamento das estruturas encefálicas que mantêm o tônus de contato com o ambiente em que o organismo se encontra, como a substância reticular ativadora ascendente. Eles oscilam entre alerta, sonolência, obnubilação, torpor e coma, quando o sujeito não está em algum dos cinco estágios do sono. A sonolência na consulta pode ser observada pela redução do fluxo de pensamento, pela diminuição do volume de temas trazidos de forma espontânea ou por uma maior dificuldade em desenvolver temas ao ser convidado a fazê-lo (MARCHETTI; CARVALHO, 2011). É importante que a sensação de que o

BARBOSA, MARQUES, SAMPAIO. Reflexões sobre a atuação do intérprete de língua de sinais na mediação da avaliação clínica em serviço de saúde mental

Belas Infiéis, v. 8, n. 1, p. 229-250, 2019. DOI: 10.26512/belasinfieis.v8.n1.2019.12985 
sujeito está mais lento, “com preguiça de falar" ou resistente a abordar os temas de forma geral seja percebida pelo intérprete de língua de sinais, seja durante a consulta, na forma de interpretar, ou após a consulta, deixando isso claro para o médico.

Uma das formas de observação dessas características é a qualidade da produção sinalizada. A partir da proposição de Andrade et al. (2017) é possível inferir que o ritmo de sinalização e a qualidade do movimento trazem informações sobre a tensão muscular durante a sinalização. Essas duas características dificilmente poderiam ser traduzidas para a fala em uma língua oral e, por isso, merecem atenção no momento da discussão clínica, parte da rotina dos serviços de saúde. Consiste na reflexão conjunta sobre o caso em discussão com a presença de mais de um profissional, da mesma área ou de outras áreas da saúde. A participação do intérprete de língua de sinais nas discussões clínicas é de grande relevância para a otimização da condução do caso.

Orientação, atenção e memória. Uma vez alerta, o sujeito precisa se localizar no tempo, no espaço e em relação a si mesmo. Prejuízos na orientação alopsíquica (tempo/espaço) ou autopsíquica (biográfica) podem estar presentes em quadros orgânicos, como a doença de Alzheimer ou intoxicações exógenas. A atenção se avalia segundo seu nível global, podendo estar aumentada (hiperprosexia) ou reduzida (hipoprosexia); e em suas especificidades, tenacidade (concentração ou capacidade de manter foco atencional) e vigilância (capacidade de dividir a atenção entre estímulos concorrentes). Momentos de hiperfoco no transtorno de déficit de atenção e hiperatividade (TDAH) se caracterizam por hipertenacidade com hipovigilância, e um paciente com delírio persecutório em episódio psicótico que não consegue concentrar sua atenção em algo e está em sobressalto por medo de ser morto pode ser descrito como em hipotenacidade com hipervigilância.

O intérprete de língua de sinais deve estar atento a estas alterações, pois pode mascarar pacientes levemente desorientados, que trazem em seu discurso incerteza em relação a onde estão fisicamente, ao ano, mês, dia ou hora atual, ou que trazem dados de sua história com temporalização confusa. Para tornar a consulta clara ao médico, o intérprete de língua de sinais pode erroneamente organizar as informações a que está tendo acesso e passar os dados com uma linearidade temporal que não foi construída pelas funções psíquicas do paciente, mas do próprio intérprete de língua de 
sinais. Prejuízos atencionais e mnêmicos percebidos pelo intérprete de língua de sinais devem ser comunicados ao médico para que possa ser avaliada sua relevância clínica.

Afetividade. O mundo afetivo é composto por um amplo pano de fundo que engendra as experiências emocionais e sentimentais, e uma expressão mais aguda e imediata. O pano de fundo, o cenário afetivo da vida psíquica, é denominado pelos psiquiatras de humor; a expressão direta da afetividade observada na consulta é chamada de afeto (RAMOS, 2006). Para transpor com qualidade estas informações, pode ser necessário enfatizar alguns dados para o médico após o término da consulta. Transmitir a carga emocional que o paciente está imprimindo em seu discurso com palavras da língua alvo pode não clarificar a intenção comunicativa expressa na língua fonte, sendo importante deixar essas ocorrências claras para o psiquiatra. Dados supra segmentais como entoação, duração, acentos e tons de determinadas palavras (ou forma de expressão do sinais), ênfase em determinados temas ou a análise perceptivo auditiva da voz (identificando qualidades como aspereza, rouquidão, soprosidade, tremor) decorrentes da manifestação de uma emoção específica no momento da avaliação são dados importantíssimos para perceber alterações como a dissociação ideo-afetiva em uma paciente com transtorno de personalidade histriônica ou a indiferença relacional de um psicopata.

Nas línguas de sinais, não faz sentido analisar a voz da pessoa surda, mas sim a qualidade da produção sinalizada. Novamente, a discussão clínica servirá como oportunidade para apontamentos dessa ordem pelo intérprete de língua de sinais. A apreciação da sinalização com análise perceptiva visual e atribuição de características, por exemplo, de tremor para a sinalização que se mostra queixosa, ou de aspereza para uma sinalização rude, tensa e rápida, são informações que podem ser cruciais ao médico para definição diagnóstica e indicação terapêutica. Essas informações são sutis, mas não podem ser omitidas.

Pensamento e linguagem. O clínico avalia o pensamento do paciente através do modelo triádico de curso, forma e conteúdo. O curso expressa a velocidade do encadeamento de ideias na fala (sinalização), aumentada, por exemplo, em uma fase maniforme e reduzida em casos de intoxicação exógena por neurodepressores. Alterações formais ocorrem quando a pessoa muda seu fluxo de pensamento, desmanchando a coerência e coesão do discurso segundo uma alteração psicopatológica típica, relacionada a algum quadro psiquiátrico (WANG et al., 2011). Por exemplo, em um descarrilhamento de pensamento de um paciente com esquizofrenia, um assunto é 
desenvolvido de forma linear e subitamente o fluxo de pensamento caminha para outro assunto, sem relação clara com o anterior, e continua seu desenvolvimento também de forma linear.

Já em um episódio maníaco desencadeado por cocaína, o pensamento pode se arborizar com associações frouxas, de forma difícil de ser compreendida. O conteúdo do discurso traz temas que são relevantes ao mundo psíquico do sujeito. Delírios de ruína, pensamentos sobrevalorados traição ou conteúdo místico-religioso ajudam muito a caracterizar o diagnóstico de forma qualitativa. Há alterações específicas de linguagem que não expressam alterações de pensamento. Elas traduzem alterações mais focais do sistema de expressão comunicativa, sendo avaliadas de forma mais específica por profissionais como o neurologista, o foniatra e o fonoaudiólogo.

A percepção do intérprete de língua de sinais para a produção atípica da língua de sinais, nesse caso, deve estar aguçada. A expressão de erros de ordem fonético-fonológica, lexical, sintática, semântica, discursiva ou pragmática podem ocorrer e carregar consigo informações relevantes para a tomada de decisão do médico com relação ao tratamento do paciente. Caso o intérprete de língua de sinais não esteja bem treinado no contexto da saúde mental, ele pode, por exemplo, omitir dados importantes do curso de pensamento ou dar à produção sentido ou coerência que não existem no discurso original, ocultando alterações formais de pensamento. Portanto, as quebras no curso do pensamento devem ser apresentadas como ocorrem, quase que em uma interpretação literal da produção em língua de sinais. Sinais ou frases irrelevantes em meio de uma resposta de um paciente surdo devem ser externalizadas com sinais ou frases também irrelevantes na língua oral, cabendo ao médico a decisão e avaliação sobre a pertinência da quebra.

Nas observações e discussões de caso realizadas no serviço em questão, em que o processo de interpretação ocorreu de forma simultânea, diante de uma dúvida sobre a coerência da produção e se identificada a necessidade esclarecimentos, acordamos que seria mais produtivo que o intérprete de língua de sinais interrompesse o turno do paciente para pedir esclarecimento ou para realizar uma observação rápida sobre a sinalização do paciente, endereçada ao médico. Essa observação ocorreria como uma "nota de rodapé" à interpretação realizada. No caso de uma observação demasiadamente invasiva, o intérprete de língua de sinais pode realizá-la em momento posterior à consulta, em discussão clínica.

Sensopercepção. Os órgãos dos sentidos imprimem sensações que são interpretadas pelo sujeito. Erros de interpretação são chamados de ilusão (o barulho de uma britadeira pode ser 
percebido de longe como o de um helicóptero) e eventos sensoperceptivos sem um objeto são chamados de alucinações (DALGALARRONDO, 2000a). O sujeito que alucina durante a consulta pode trazer ao intérprete sentimentos muito diversos, como medo, vivência místico-religiosa ou fascinação. É importante que o intérprete de língua de sinais esteja preparado para este evento psicopatológico, visto que experiências pessoais como a ideia de que há um espírito na sala ou a sedução por algo tão diferente e interessante frequentemente tiram o intérprete de sua posição profissional e o colocam em um lugar de desconforto ou mórbida curiosidade, prejudicando muito a qualidade do trabalho e da relação terapêutica.

A interpretação de sinalização que pode parecer não relevante para o intérprete de língua de sinais pode ser crucial para a identificação, pelo médico, de uma alucinação. Diante de um paciente surdo que dirige sua sinalização a um local específico do ambiente em que não se encontre um possível interlocutor, como se estivesse conversando com alguém, a interpretação deve acontecer como se fosse pertinente à interação médico-paciente, dado este observado em dois atendimentos do serviço no qual se baseou nossa reflexão.

Inteligência. Testes completos de inteligência, especialmente com quantificação do quoeficiente de inteligência, requerem uma avaliação neuropsicológica formal. Na prática clínica, a inteligência é avaliada segundo a capacidade de resolução de problemas do sujeito, dados os recursos que estão disponíveis naquele momento, lidando com abstrações e situações novas (TENG ET AL., 2011). A aplicação de testes objetivos sem o prévio treinamento do intérprete de língua de sinais pode fazer com que eles sejam transmitidos ao paciente de forma explicada, camuflando a validade e a confiabilidade do teste e dos dados obtidos a partir de um enunciado com pistas das respostas esperadas. Apresentar questões ao paciente e devolver respostas ao psiquiatra requer afinamento técnico e treinamento. Perguntas como "O que fazer se você vê uma criança próxima ao trilho do metrô?", "Se o vento está soprando uma bandeira para noroeste, de onde está vindo o vento?" e “O que é justiça?” podem ser desafiadoras tanto para interpretar para o paciente sem oferecer respostas, quanto para traduzir para o médico de forma adequada e que contribua para a avaliação real da inteligência do paciente.

Juízo e crítica. O juízo de realidade fala sobre a capacidade do sujeito de julgar as informações que ele obtém do ambiente para estruturar sua concepção de realidade. O delírio é a patologia desta função mental, em que o indivíduo tem acesso aos dados sensoperceptivos e os

BARBOSA, MARQUES, SAMPAIO. Reflexões sobre a atuação do intérprete de língua de sinais na mediação da avaliação clínica em serviço de saúde mental

Belas Infiéis, v. 8, n. 1, p. 229-250, 2019. DOI: 10.26512/belasinfieis.v8.n1.2019.12985 
interpreta de modo desconectado da realidade (DALGALARRONDO, 2000b). Na experiência clínica de um dos autores, um paciente ouvinte internado por quadro descompensado de esquizofrenia referia que o barulho do balançar das folhas da árvore ao lado de sua janela era um sinal de que seu primo, "dono do hospital" (o hospital é da rede pública), estava organizando um plano para matá-lo. Delírios estruturados podem ter conteúdos dos mais diversos, como de persecutoriedade, místico-religioso, de grandeza ou ruína. Ideias sobrevaloradas e deliroides são outras formas de apresentação destes eventos psíquicos de forma mais branda.

A ideia deliroide tem a forma de delírio, mas sem sua cristalização invulnerável a argumentação e deformação do mundo psíquico associada. Já a ideia sobrevalorada é um fenômeno psíquico observado mesmo em pessoas sem diagnóstico psiquiátrico, quando um conteúdo de pensamento se torna marcadamente prioritário, com destacada redução de importância de outros temas. A crítica da doença ou nosognosia descreve a capacidade do sujeito de observar a característica patológica de seus sintomas. Ciúmes e preocupação com a própria saúde são eventos psíquicos normais, mas não conseguir perceber-se envolvido em um contexto de ciúmes patológicos ou hipocondria é um sinal cardinal de transtorno mental. A preocupação com o fato de estar tendo uma alucinação em contraste com aceitar naturalmente o evento psicopatológico como um fato real é um importante dado na avaliação clínica. Portanto, sendo uma demanda do EP, o intérprete de língua de sinais precisa desenvolver a sensibilidade para perceber a relação que o paciente desenvolve com os fenômenos psíquicos que traz em seu discurso. Falar deles com estranhamento e distanciamento aponta para um quadro clínico muito diferente de descrevê-los como se descreve um fato observável e compartilhado publicamente.

Psicomotricidade. Ouvintes não treinados em língua de sinais e/ou sem contato com a comunidade surda eventualmente consideram exageradas as expressões não manuais utilizadas pelo paciente surdo. Como as línguas de sinais são línguas visuoespaciais, um paciente sinalizando de forma habitual ou tentando dar ênfase em alguns temas pode ser visto por um médico inexperiente com a língua de sinais como agitado ou inquieto, mesmo que a interpretação para a língua oral esteja acontecendo de forma adequada e esperada para uma língua oral. Entretanto, alterações de psicomotricidade podem ocorrer e indicar condições patológicas (SALLET \& GORDON, 2011), como a ansiedade relacionada ao falar sobre um abuso sexual na infância, a agitação em um quadro de psicose secundária ou o uso de cannabis.

BARBOSA, MARQUES, SAMPAIO. Reflexões sobre a atuação do intérprete de língua de sinais na mediação da avaliação clínica em serviço de saúde mental

Belas Infiéis, v. 8, n. 1, p. 229-250, 2019. DOI: 10.26512/belasinfieis.v8.n1.2019.12985 
Novamente a qualidade da produção sinalizada (ANDRADE et al., 2017) entra em questão na atuação do intérprete de língua de sinais. Identificar a fronteira entre o que é a ênfase na sinalização e o que é atípico na realização do movimento (por exemplo, com relação à amplitude de sua realização) é atividade do intérprete de língua de sinais. Não estando o habituado a quadros psiquiátricos e não direcionando ao médico com competência as informações necessárias, ele pode produzir uma avaliação deficitária da psicomotricidade.

Vontade/conação. A capacidade de realizar ações orientadas para um fim relevante é uma síntese de diversas funções psíquicas, sendo, portanto, de alguma forma impactada em grande parte dos transtornos mentais. Ao conhecer não somente os sinais usados na consulta e a gramática da língua, mas também o contexto mais amplo da cultura surda, o intérprete de língua de sinais pode clarificar para o psiquiatra algumas formas usuais de se colocar no mundo do surdo. Aqui são avaliadas representações volitivas, tomada de decisão e pragmatismo ${ }^{4}$. Um pragmatismo preservado pressupõe capacidade de realizar atividades mais simples de autocuidado, como tomar banho sozinho e sem necessidade de lembrança ou estímulo; atividades mais elaboradas, como preparar uma refeição ou planejar (e realizar) uma saída com amigos; e complexas, como desenvolver um projeto ou escrever um trabalho de conclusão de curso. Não ter vontade de interagir com familiares ou isolar-se pode ser sinal, por exemplo, de que o antidepressivo precisa ter sua dose ajustada ou que o desinteresse da família em aprender língua de sinais precisa ser abordado. Sem a mediação cultural feita pelo intérprete de língua de sinais para um psiquiatra com pouca experiência em atender surdos, dados importantes no atendimento podem ser negligenciados e o paciente pode ser mais medicado do que o necessário.

Do ponto de vista linguístico, a capacidade de realizar ações orientadas para um fim relevante se concretiza na interação comunicativa adequada. Há situações clínicas desafiadoras, como pacientes surdos que não toleram serem contrariados ou que simplesmente ignoram a interação médico-paciente, se concentrando unicamente em si e em falar de assuntos de seu interesse, repetidamente. Esse tipo de discurso repetitivo traz consigo alterações na sinalização do paciente surdo por não ter uma resposta positiva às suas ações.

Há, de um lado, o médico, que procura estabelecer uma comunicação intencional, e, do outro lado, um paciente que se recusa a interagir, perseverando no mesmo tema e apresentando uma viscosidade temática. O intérprete de língua de sinais deve estar atento a esse tipo de 
perseveração de tema e procurar retratar a situação tal qual ela acontece, no sentido de que, se o surdo repetir o sinal inúmeras vezes, essa informação deve ser interpretada na mesma proporção repetidamente; se o surdo sinalizar de uma forma mais tensa ou rápida, isso também deve ser dito. O intérprete de língua de sinais não deve simplificar a informação, e é de suma importância que aspectos tanto da frequência das repetições quanto da tensão de sinalização sejam igualmente expostos ao médico. Estes conhecimentos específicos presentes nos sinais extrapolam a simples informação acerca do que aquele sinal representa e, em se tratando de pacientes surdos de saúde mental que usam língua de sinais, são importantes e tendem a interferir diretamente no diagnóstico médico.

Ideação suicida. Vários quadros psiquiátricos e situações existenciais entram em contato com a temática do suicídio. Esse caminho vai desde ideias de sumir ou de deixar tudo para trás, de dormir e não mais acordar, ou de que a morte seria uma boa opção para resolver os problemas, passando por ideação efetivamente suicida, até esboços de planejamento, como: pensar no método de tirar a própria vida, culminando em verbalizações para outras pessoas; elaborar um planejamento estruturado (definir uma data) ou engajar-se em ações reais, com comportamento parassuicida (atravessar a rua sem olhar para os lados, parar tratamento antiretroviral para HIV); preparar-se para a morte (deixar carta de despedida, fechar conta no banco), até a tentativa de suicídio. O tema suicídio mobiliza subjetivamente todos os que têm contato com ele e de várias formas.

O intérprete de língua de sinais precisa estar treinado para lidar com a situação e atento ao modo como faz a intermediação de informações para o clínico. Questões emocionais de ordem pessoal podem se misturar com questões típicas do atendimento. A reflexão desses elementos é central às discussões em saúde mental. Pontualmente não tivemos essa questão levantada dessa forma no referido serviço aqui analisado, mas consideramos essencial que os intérpretes estejam atentos a possíveis situações como: o intérprete de língua de sinais pode ficar com medo de o paciente de fato se matar e se sentir antecipadamente culpado, fazendo com que ele sobrevalorize uma experiência que pode ainda estar pouco estruturada e sem risco iminente à vida, ou pode, por exemplo, ter posições pessoais de cunho religioso frente ao suicídio e não transmitir informações importantes, reproduzindo o contexto irreal, mas culturalmente sancionado do "vamos falar sobre outra coisa" ou "não vamos falar disso para não dar ideia". 
Por isso, as pistas linguísticas que podem ser expressas devem ser interpretadas com cuidado, sem sofrer juízo de valor por parte do intérprete de língua de sinais. Nesse ponto, as escolhas lexicais realizadas no momento da interpretação são importantes para que as informações expressas na língua fonte não sofram modificações substanciais quando veiculadas na língua alvo.

Súmula psicopatológica. Essa é a parte mais sutil da avaliação psicopatológica, onde se resumem com jargões simples os achados do EP e se organizam metalinguisticamente os dados que não couberam em toda a avaliação do Estado Mental. O tom da consulta e como as notas relacionais ressoam no psiquiatra são imprescindíveis à boa diagnose e indicação terapêutica. Uma pessoa que está ocultando informações pode estar tentando fazê-lo para não deixar escapar informações que inviabilizem sua construção simulada de doença, em uma situação em que esteja fingindo um quadro para buscar um atestado médico, ou por estar desconfiada do clínico devido a um quadro psicótico delirante. Os sentimentos evocados no psiquiatra frente aos dados apresentados, intuições sobre o contato que aconteceu e a presunção de validade dos fenômenos observados são importantes informações a serem julgadas durante a avaliação.

As informações linguísticas que constroem o tom da consulta passaram continuamente pela interpretação do intérprete de língua de sinais, de forma que o processo diagnóstico foi, a todo o momento, mediado pelo conhecimento de língua (oral e de sinais), pelo conhecimento cultural e pelas impressões subjetivas do indivíduo que atuou na mediação. É claro que o médico possui ferramentas de análise que levam em consideração a mediação e os possíveis ruídos que ela apresenta, mas o conhecimento pelo intérprete de língua de sinais das necessidades do médico no momento da consulta são de extrema valia e concorrem para a eficácia do tratamento.

É importante a treinamento específico do intérprete de língua de sinais no contexto da saúde, preferencialmente com foco em saúde mental, para garantir a confiabilidade dos dados transmitidos ao psiquiatra. Caso isso não seja garantido, há risco de que informações importantes (como um tom de indiferença na consulta) sejam desvalorizadas, informações habituais (como ideação suicida) sejam supervalorizadas e dados clínicos sejam modificados (uma forma exaltada de expressão de sofrimento pode ser transmitida ao médico como um quadro muito grave).

BARBOSA, MARQUES, SAMPAIO. Reflexões sobre a atuação do intérprete de língua de sinais na mediação da avaliação clínica em serviço de saúde mental

Belas Infiéis, v. 8, n. 1, p. 229-250, 2019. DOI: 10.26512/belasinfieis.v8.n1.2019.12985 


\section{Considerações Finais}

A atuação do intérprete de língua de sinais na mediação da relação médico-paciente deve prever a existência da língua de sinais atípica. As interações espontâneas típicas apresentam quebras conversacionais, mas quando estão sendo conduzidas por indivíduos sem problemas de linguagem, o princípio da cooperação, somado ao processamento típico de língua, permite que essas interações ocorram de forma harmônica do ponto de vista linguístico-pragmático: as quebras são revistas imediatamente, as pressuposições são elucidadas no decorrer da interação, as sobreposições de turno são satisfeitas pela cooperação entre os interlocutores e os conflitos de tema são resolvidos com negociação.

Entretanto, diante de um interlocutor surdo com língua de sinais atípica ou com desordens que, momentaneamente ou não, o fazem expressar uma produção linguística atípica, as quebras comunicativas podem ocorrer com uma frequência maior quando comparadas às interações normais, e muitas vezes sem resoluçães que permitam a correção ou adequação dessas quebras. Quando essas interações atípicas são mediadas por intérprete de língua de sinais e ocorrem em situações em que o conteúdo referencial ou a efetividade da comunicação é suficiente para satisfazer os interesses dos interlocutores, o intérprete pode não mobilizar as informações relativas à atipicidade para o interlocutor ouvinte. Quando a interação tem objetivos específicos, como a investigação do perfil psíquico da pessoa surda com língua de sinais atípica, os eventos que se caracterizam como atípicos devem ser veiculados para a língua alvo: são essenciais para que o interesse de um dos atores da interação seja satisfeito.

Esta não é uma tarefa trivial do intérprete de língua de sinais. Antes, apresenta um grau de sofisticação que o faz mobilizar, além dos conhecimentos de língua e de interpretação e funções cognitivas habitualmente usadas para esse processo, o conhecimento específico metalinguístico da língua de sinais, da sua estrutura e da sua produção típica e atípica. A percepção, análise e interpretação do que é observado nas entrelinhas da produção do paciente surdo e nas sobreposições de linhas na interação entre o paciente surdo e o médico deve ser exercitada, pois são possibilidades que podem direcionar os critérios do Exame Psíquico a ser realizado. Essas habilidades devem fazer parte da formação de intérprete de língua de sinais que pretendem atuar em serviços de saúde, especialmente nos serviços de saúde mental. 
Da mesma forma, para o campo da Saúde Mental, o contato com outras disciplinas é fundamental para promover transdisciplinaridade e intensificar reflexões. A avaliação psiquiátrica tem como objetivos a elucidação do diagnóstico que traz sofrimento e delineia a queixa, e a estruturação de um plano terapêutico singular para o cliente. A clínica psiquiátrica é um convite para repensar o Exame Psíquico à luz dos Estudos da Tradução, com a colaboração da Fonoaudiologia e da Linguística. A prática é permeada pela análise de padrões linguísticos que sinalizam alterações psicopatológicas, mas o treinamento médico frequentemente não é permeado por esses campos de saber. Permanece como um desafio para a Saúde Mental o aprofundamento de discussões com as humanidades, especialmente com áreas que apresentam importantes contribuições ao estudo da maior ferramenta de diagnóstico e tratamento do psiquiatra: o discurso.

\section{REFERÊNCIAS BIBLIOGRÁFICAS}

ANDRADE, C. R. F.; JUSTE, F. S.; BARBOSA, F. V.; ALVES, R. C.; MOURA, G. M. Avaliação da Fluência de Sinalização na Libras. IN: BARBOSA, Felipe Venâncio; NEVES, Sylvia Lia Grespan (Org.). Língua de Sinais e Cognição - LiSCo: Estudos em avaliação fonoaudiológica baseada na Língua Brasileira de Sinais. 1ed. Barueri: Pró-Fono, 2017, v. 1, p. 45-56.

ATKINSON, J.; MARSHALL, J.; WOLL, B.; THACKER, A. Testing Comprehension Abilities in Users of British Sign Language following CVA. Brain and Language: Amsterdam, v. 94, n. 22, Ago, 2005.

BARBOSA, F. V. As Interferências no Processamento da Linguagem de um Adolescente Surdo com Lesão Cerebral. In: Simpósio Linguística e Cognição, 2007, Belo Horizonte. Trabalho Apresentado no Evento. Belo Horizonte: Faculdade de Letras da UFMG, 2007.

BARBOSA, F. V. Language Processing Interferences in a Sign Language Produced by a Deaf With Brain Injury. Trabalho Apresentado ao Language Impairment in Monolingual and Bilingual Society - LIMoBiS. Aalborg, 2010.

BARBOSA, F. V. A Clínica Fonoaudiológica Bilíngue e a Escola de Surdos na Identificação da Língua de Sinais Atípica. Educação e Realidade, v. 41, p. 731-754, Set. 2016.

BARBOSA, F. V. Triagem de Habilidades Linguísticas da Língua Brasileira de Sinais. IN: BARBOSA, F. V.; NEVES, S. L. G. (Org.). Língua de Sinais e Cognição - LiSCo: Estudos em avaliação fonoaudiológica baseada na Língua Brasileira de Sinais. 1. ed. Barueri: Pró-Fono Editora, v. 1, p. 1-24, 2017.

BARBOSA, MARQUES, SAMPAIO. Reflexões sobre a atuação do intérprete de língua de sinais na mediação da avaliação clínica em serviço de saúde mental

Belas Infiéis, v. 8, n. 1, p. 229-250, 2019. DOI: 10.26512/belasinfieis.v8.n1.2019.12985 
BARBOSA, F. V.; LICHTIG, I. Protocolo do perfil das habilidades de comunicação de crianças surdas. Revista de Estudos da Linguagem, v. 22, n.1, p. 95-118, Jun. 2014.

BARBOSA, F. V.; NEVES, S. L. G. (Org.). Língua de Sinais e Cognição - LiSCo: Estudos em avaliação fonoaudiológica baseada na Língua Brasileira de Sinais. 1. ed. Barueri: Pró-Fono Editora, v. 1. 162p., 2017.

BRASIL. Conselho Nacional de Secretários de Saúde. Assistência de Média e Alta Complexidade no SUS / Conselho Nacional de Secretários de Saúde. - Brasília: CONASS, 2007. Disponível em: http://bvsms.saude.gov.br/bvs/publicacoes/colec_progestores_livro9.pdf. Acesso em: 19 de março de 2018.

CASSOL, M.; REPPOLD, C. T.; FERÃO, Y.; GURGEL, L. G.; ALMADA, C. P. Análise de características vocais e de aspectos psicológicos em indivíduos com transtorno obsessivocompulsivo. Revista da Sociedade Brasileira de Fonoaudiologia, São Paulo, v. 15, n. 4, p. 491-496, Dez. 2010.

CHANTRAINE, Y.; JOANETTE, Y.; CARDEBAT, D. Impairments of discourse-level representations and processes. In: B. STEMMER; H. A. WHITAKER (Eds.). Handbook of

Neurolinguistics (p. 262-275). London: Academic Press, 1998.

COSTA, H. O.; MATIAS, C. O impacto da voz na qualidade da vida da mulher idosa. Revista Brasileira de Otorrinolaringol. v.71, n. 2, p. 172-178, Abr. 2005.

CUMMingS, L. Clinical Pragmatics In: CUMMINGS, L. (ed.) The Routledge Pragmatics Encyclopedia. Abingdon, Oxon: Routledge, 2010.

DALGALARRONDO, P. Psicopatologia e semiologia dos transtornos mentais. Porto Alegre: Editora Artes Médicas do Sul, 2000a, p. 124.

DEWART, H.; SUMMERS, S. The Pragmatics Profile of Early Communication Skills. 2 ed. Windsor: NFER-Nelson, 1994.

FAROOQ, S.; FEAR, C.; OYEBODE, F. An investigation of the adequacy of psychiatric interviews conducted through an interpreter. Psychological Bulletin, v.21, n.4, p. 209-213, Abr. 1997.

FERNANDES, F.; DREUX, M. Autismo Infantil: repensando o enfoque fonoaudiológico: aspectos funcionais da comunicação. São Paulo: Lovise, 1996.

FERREIRA, Ademir Pacelli; NETTO, Vitor Mello. O ensino da clínica psicopatológica: o caso da sessão clínica. Rev. latinoam. psicopatol. fundam., São Paulo , v. 12, n. 3, p. 481-496, Set. 2009. 
FLORES, G. The Impact of Medical Interpreter Services on the Quality of Health Care: A Systematic Review. Medical Care Research and Review, Vol. 62, n. 3, p. 255-299, Jun. 2005.

GILE, D. The Effort Models in Interpretation. In: Basic Concepts and Models for Interpreter and Translator Training. Amsterdam/Philadelphia: John Benjamins, 1995, p. 159-190.

GERBER, S.; GURLAND, G. B. Applied Pragmatics in the Assessment of Aphasia. Seminars in Speech and Language, v. 10, n. 4, p. 263-279, 1989.

HOUGH, M. S.; PIERCE, R. S. Pragmatics and Treatment. In: CHAPEY, R. Language Intervention Strategies in Adult Aphasia. Williams \& Williams, Baltimore, 1993.

LEE, T. H. Ear Voice Span in English into Korean Simultaneous Interpretation. Meta: Translators' Journal, vol. 47, n. 4, 596-606, Dez. 2002.

MARCHETTI, R. L.; CARVALHO, V. B. Consciência e Atenção. In: MIGUEL E.C.; GENTIL V.; GATTAZ W. F. (org.). Clínica Psiquiátrica. $1^{a}$ ed. Barueri: Manole, 2011. p. 451-468.

MASON, K.; ROWLEY, K.; MARSHALL, C.; ATKINSON, J.; HERMAN, R.; WOLL, B.; MORGAN, G. Identifying Specific Language Impairment in Deaf Children Acquiring British Sign Language: implications for theory and practice. British Journal of Developmental Psychology, v. 28, v.1, p. 33-50, Mar. 2010.

METZGER, M. Interactive Roleplays as a teaching strategy. In: ROY, C (ed.). Innovative Practices for Teaching Sign Language Interpreters. Washington, D.C.: Gallaudet University Press, 2000. p. 83-108.

RAMOS, R. T. O exame psíquico. In: ABREU C. N.; SALZANO F. T.; VASQUES F.; FILHO R. C.; CORDÁS, T. A. Síndromes psiquiátricas: diagnóstico e entrevista para profissionais de saúde mental. Porto Alegre: Artmed, 2006. p. 25-29.

SALLET P. C.; GORDON, P. C. Alterações da psicomotricidade. In: MIGUEL, E. C.; GENTIL, V.; GATTAZ, W. F. (org.). Clínica Psiquiátrica. 1ª ed. Barueri: Manole, 2011. p. 550-56.

SAVIGNON, S. Beyond Communicative Language Teaching: what's ahead? Journal of Pragmatics, Amsterdam, v. 39, v.1, p. 207-220, Jan. 2007.

TENG C. T.; FALCÃO, M. I.; TAVEIRA A. Alterações das funções cognitivas: Memória e inteligência. In: MIGUEL, E. C.; GENTIL, V.; GATTAZ, W. F. (org.). Clínica Psiquiátrica. $1^{\text {a }}$ ed. Barueri: Manole, 2011. p. 469-488.

VAN HERREWEGHE, M. Teaching turn-taking and turn-yielding in meetings with deaf and hearing participants. In.: ROY, C. B. (ed.) Advances in Teaching Sign Language Interpreters. Washington, D.C.: Gallaudet University Press, 2005.

BARBOSA, MARQUES, SAMPAIO. Reflexões sobre a atuação do intérprete de língua de sinais na mediação da avaliação clínica em serviço de saúde mental

Belas Infiéis, v. 8, n. 1, p. 229-250, 2019. DOI: 10.26512/belasinfieis.v8.n1.2019.12985 
WANG Y-P.; BIONDO, M.; MACHADO, B. H.; LOCH A. A. Alterações do pensamento (forma e conteúdo) e linguagem. In: MIGUEL, E. C.; GENTIL V.; GATTAZ, W.F. (org.). Clínica

Psiquiátrica. $1^{\mathrm{a}}$ ed. Barueri: Manole, 2011. p. 504-518.

WOLL, B.; MORGAN, G. Language Impairments in the Development of Sign: do they reside in a specific modality or are they modality-independent deficits? Bilingualism, Language $\boldsymbol{\&}$

Cognition, Cambridge, v. 15, n.1, p. 75-87, Jan. 2012.

\begin{abstract}
${ }^{i}$ Felipe Venâncio BARBOSA - Doutor em Ciências da Reabilitação (2007) pela Universidade de São Paulo. Graduado em Fonoaudiologia (2001) pela mesma instituição. É professor da Universidade de São Paulo. Realizou estágio de pósdoutorado (2013) na University College London, Inglaterra. São Paulo, São Paulo, Brasil.

Lattes: http://lattes.cnpq.br/7530556224930517 E-mail: felipebarbosa@usp.br

ii Janice Gonçalves Temoteo MARQUES - Doutora em Psicologia Experimental (2012) pela Universidade de São Paulo. Mestre em Letras (2008) pela Universidade Federal da Paraíba. Especialista em no Ensino da Língua Inglesa. (2006) e Graduada em Língua Portuguesa, Língua Inglesa (2005) pela Universidade Regional do Cariri. É professora na Universidade Estadual de Campinas. Campinas, São Paulo, Brasil.

Lattes: http://lattes.cnpq.br/1464854130047784 E-mail: janicetemoteo@gmail.com

iii Leonardo Augusto Negreiros Parente Capela SAMPAIO - Mestrando em medicina na Universidade de São Paulo. Mestrado profissionalizante em MBA executivo: Gestão de Clínicas e Hospitais (2016) pela Fundação Getúlio Vargas. Especialista em psiquiatria (2014) pela Universidade de São Paulo. Bacharel em Medicina (2008) pela Universidade 250 de Fortaleza. Coordenador do Programa de Psiquiatria Social e Cultural do Instituto de Psiquiatria do Hospital das Clínicas da Faculdade de Medicina da Universidade de São Paulo - Prosol IPq HCFMUSP. São Paulo, São Paulo, Brasil.
\end{abstract}

Lattes: http://lattes.cnpq.br/7698564170175824 E-mail: leosampaiu@ gmail.com

${ }^{1}$ A definição de Pragmática apresentada aqui toma como base autores da área clínica, como Dewart e Summers (1994), Fernandes (1996) e Lichtig e Barbosa (2014), assim como a definição de Pragmática Clínica apresentada por Cummings (2010) na obra The Routledge Pragmatics Encyclopedia, por ele editada.

${ }^{2}$ Os distúrbios de linguagem e as falhas comuns no processamento da linguagem, tradicionalmente observadas nos estudos de línguas orais, podem ser expressas na compreensão e/ou produção das línguas de sinais. Da mesma forma como o estudo das produções atípicas das línguas orais tem, ao longo de décadas, contribuído para a compreensão da linguagem humana, as manifestações de desordens da linguagem nas línguas de sinais podem, além de beneficiar pessoas surdas que necessitam de intervenção clínica, trazer informações importantes sobre as línguas.

${ }^{3}$ Entende-se por nível terciário o conjunto de serviços de alta complexidade do Sistema Único de Saúde (SUS), de caráter docente e assistencial e com recursos humanos especializados (Brasil, 2007).

${ }^{4}$ Pragmatismo é o termo utilizado no Exame Psíquico para descrever a capacidade de iniciar e interromper ações, e realizar ações da vida prática (RAMOS, 2006). Não faz referência à corrente filosófica do Pragmatismo ou ao campo linguístico da Pragmática.

BARBOSA, MARQUES, SAMPAIO. Reflexões sobre a atuação do intérprete de língua de sinais na mediação da avaliação clínica em serviço de saúde mental

Belas Infiéis, v. 8, n. 1, p. 229-250, 2019. DOI: 10.26512/belasinfieis.v8.n1.2019.12985 